\title{
Recent development in liquid chromatography stationary phases for separation of Traditional Chinese Medicine components
}

Hongli Jin, Yanfang Liu,** Zhimou Guo, Jixia, Wang, Xiuli Zhang, Chaoran Wang, Xinmiao Liang*

Key Lab of Separation Science for Analytical Chemistry, Dalian Institute of Chemical Physics, Chinese Academy of Sciences, Dalian 116023, People's Republic of China

Fax: +86-411-84379539

Email: liangxm@dicp.ac.cn
Tel.: +86-411-84379541

liuyanfang@dicp.ac.cn

Keywords: Traditional Chinese Medicines / Stationary phases / High performance liquid chromatography / Hydrophilic interaction liquid chromatography / Ultra high-performance liquid chromatography 


\begin{abstract}
Traditional Chinese Medicine (TCM) is an ancient medical practice which has been used to prevent and cure diseases for thousands of years. TCMs are frequently multi-component systems with mainly unidentified constituents. The study of the chemical compositions of TCMs remains a hotspot of research. Different strategies have been developed to manage the significant complexity of TCMs, in an attempt to determine their constituents. Reversed-phase liquid chromatography (RPLC) is still the method of choice for the separation of TCMs, but has many problems related to limited selectivity. Recently, enormous efforts have been concentrated on the development of efficient liquid chromatography (LC) methods for TCMs, based on selective stationary phases. This can improve the resolution and peak capacity considerably. In addition, high-efficiency stationary phases have been applied in the analysis of TCMs since the invention of ultra high-performance liquid chromatography (UHPLC). This review describes the advances in LC methods in TCM research from 2010 to date, and focuses on novel stationary phases. Their potential in the separation of TCMs using relevant applications is also demonstrated.
\end{abstract}




\section{Contents}

1. Introduction

2. Selective stationary phases for TCMs.

1.1 Hydrophilic interaction liquid chromatography (HILIC) stationary phases

1.1.1 Recent development in HILIC stationary phases

1.1.2 Application of HILIC stationary phases in TCMs

1.2 Polar-modified reversed-phase liquid chromatography (RPLC) stationary phases

1.2.1 Recent development in polar-modified RPLC stationary phases

1.2.2 Application of polar-modified RPLC stationary phases in TCMs

3. High-efficiency stationary phases for TCMs

4. Concolusion

Acknowledgements

Reference 


\section{Introduction}

Traditional Chinese Medicines (TCMs) have a broad range of medical applications, which were developed in ancient China, based on a tradition of more than 2,000 years. TCMs are widely used to prevent and cure illness in China, and have attracted worldwide interest in recent years, due to their mild efficacy and fewer side effects. It was estimated that TCMs are used by more than 1.5 billion people worldwide [1]. TCMs are multi-component systems produced from plant materials, containing hundreds or even thousands of compounds [2-4]. However, there has been very limited knowledge known on their properties, which is a bottleneck to the modernization and globalization of TCMs. The investigation of chemical compositions of TCMs remains a research hotspot.

The separation of TCMs plays a vital role in the phytochemical identification. Various separation strategies have been used in this area [5-8]. High performance liquid chromatography (HPLC) is perceived to be one of the most powerful separation techniques, providing many advantages over other chromatographic methods, such as high capacity and good reproducibility [9]. Common chromatographic techniques include reversed-phase liquid chromatography (RPLC), normal-phase liquid phase (NPLC), hydrophilic interaction liquid phase (HILIC), and ion-exchange chromatography (IEC). These chromatographic techniques are capable of offering different separation selectivities, which enables more flexible separation. HPLC is currently used extensively in the separation of TCMs [10-14].

Stationary phases, the core of HPLC technology, are the foundation of chromatographic methods. To date, conventional RP C18 stationary phases have been the most commonly used to isolate TCM compounds [13, 15-18]. Nevertheless, these phases are unable to provide satisfactory separation, such as insufficient resolution and peak capacity. This is mainly due to the limited selectivity. In recent years, there has been intense research into the development of selective stationary phases to offer an alternative but complementary separation to conventional RPLC stationary phases. And two-dimensional liquid chromatography (2D-LC) provides a great increase in separation ability and peak capacity. The selective stationary phases are useful to the construction of orthogonal multidimensional systems for TCM research $[19,20]$. Moreover, high-efficiency separation has become an important trend in the analysis of TCMs. high-performance liquid chromatography (UHPLC) with sub-2 $\mu \mathrm{m}$ particle 
columns are increasing concerned in this area [21-24]. In this article, we review the recent advances in LC methods in TCMs from 2010 up to date, and focus on novel LC stationary phases. The potential of these phases is demonstrated with relevant applications.

\section{Selective stationary phases for TCMs}

\subsection{HILIC stationary phases}

\subsubsection{Recent development in HILIC stationary phases}

HILIC, suggested by Alpert in 1990 [25], is a chromatographic technique in which analytes interact on a hydrophilic stationary phase and are eluted with a relatively hydrophobic binary eluent. In HILIC, water is the stronger eluting member (the main component is usually being 5\%-40\% water in acetonitrile). HILIC has been steadily gaining interest for its different separation selectivity to RPLC, and has emerged as a potent chromatographic method for polar analytes [26-28].

HILIC stationary phases are usually silica-based where the surface is modified by polar functional groups [29]. In the early days, HILIC was considered as "high aqueous NP" chromatography, and thus the stationary phases were all based on

underivatized, aminopropyl-bonded, and diol-bonded silica etc. However, problems concerning hydrophilicity, selectivity, and stability were encountered. In recent years, the development of special separation materials for HILIC has attracted more and mroe attention [30]. The number of commercially available columns designed especially for HILIC is growing, such as amide-based, poly (succinimide)-based, saccharides-based, and zwitterion-based stationary phases. In 2014, our group reviewed the development and application of HILIC stationary phases [31].

Recently, Qiao et al. [32] prepared an imidazolium-embedded $N$, $N$-dimethylamiopropyl functionalized silica-based stationary phase ( $\mathrm{Sil}-\mathrm{ImCl}$ ), which was used for HILIC/RPLC mixed-mode chromatography. The synthesized stationary phase was successfully applied in the separation of nucleosides, water-soluble vitamins, phenols, and positional isomers. Xiao et al. [33] reported a HILIC stationary phase based on thiourea derivative modified silica. Thiourea derivative was grafted onto the surface of silica particles via a mild addition reaction between $-\mathrm{NH}_{2}$ and $-\mathrm{SCN}$. The stationary phase performed unique selectivity in the separation of polar and hydrophilic analytes. Zhang et al. [34] developed an arginine-functionalized stationary phase for HILIC by clicking arginine onto silica gel. This stationary phase 
provided good separation quality of organic acids and sugars. In the same group, multiple layers of polyvinyl alcohol (PVA) coating are generated onto silica gel by thermal immobilization to form a stationary phase used for HILIC. The synthesized stationary phase showed high efficiency and high chemical stability [35].

In our group, a controlled thiol-initiated surface polymerization strategy was developed and employed to prepare hydrophilic polymer stationary phases, which performed excellent chromatographic performance and protein non-fouling properties [36]. In addition, glyco-silica materials were prepared based on thiol-ene click chemistry between alkene-saccharides and mercapto-silica, which presented good HILIC separation [37].

\subsubsection{Application of HILIC stationary phases in TCMs}

Considerable interest in HILIC has inspired the development of chromatographic materials. HILIC stationary phases have gradually found applications in the separation and purification of chemical components from TCMs, including glycosides, oligosaccharides, steroids, and phenolic acids.

\subsubsection{Glycosides}

The polarity of stationary phases makes HILIC columns suitable to separate glycosides (e.g., saponin, quinochalcone C-glycosides and stevioside etc.) [38-40]. These compounds commonly consist of aglycones coupled to sugar chain units, resulting in good retention on HILIC stationary phases in most cases. Besides, due to the different retention mechanisms between HILIC and RPLC, the coupling of these two chromatographic modes performs excellent orthogonality for glycosides.

Saponins, typical glycosides, are the main ingredients in many TCMs [41]. These compounds possess diverse pharmacological activities [42, 43]. Jin et al. [44] developed a comprehensive off-line 2D-HILIC/RPLC method to detect saponins in extracts of Panax notoginseng, based on an Acchrom XAmide column and an UHPLC BEH C18 column. The orthogonality of the 2D-HILIC/RPLC was up to $81 \%$, and the peak capacity was 10200. In total, 224 saponins were detected, and some of them were minor amounts. In our group, a 2D-RPLC/HILIC purification method was constructed to separate saponins from $P$. notoginseng [39]. Good column orthogonality was obtained by using a C18 column and an XAmide column. As a result, eight saponins, including two pairs of isomeric saponins and one new saponin, were isolated and identified. 
Natural saponins have considerable structural diversity and many are structurally similar or even isomeric. A HILIC stationary phase (named Click XIon) was used to the selective separation of isomeric saponins [45]. Compared to other commercial HILIC columns, the Click Xlon column exhibited the strongest hydrophilic retention for a set of isomeric saponins, including ginsenoside Rc (S1), ginsenoside Rb-2 (S2), and ginsenoside Rb-3 (S3) (Fig. 1). Taking the extracts of Panax notoginseng as an example, eleven saponins, including three sets of isomeric saponins with one new saponin were purified on the Click Xlon column, and identified by MS and NMR.

Quinochalcone C-glycosides (QCGs) are a series of pharmacologically bioactive components in Carthamus tinctorius L. Guo et al. [40] established an offline 2D-HILIC/RPLC system for the characterization of QCGs in C. tinctorius L. by the combination of an Acchrom XAmide column and a BEH Shield RP-C18 column. The evaluation results showed that the orthogonality of this 2D-LC system was $71 \%$, and the theoretical peak capacity reached 7654. Following coupling of the 2D-LC system and linear ion-trap quadrupole/Orbitrap mass spectrometry, 163 QCG homologs were putatively characterized from C. tinctorius L., and 149 of these were potentially new homologs.

Anthocyanins, a class of heterosides, are widespread in natural plants, conferring attractive colors (red and blue) to them. A HILIC method was developed to efficiently purify a challenging anthocyanin from Lycium ruthenicum Murray with a Click Xlon zwitterionic stationary phase [46]. The experimental data showed that the use of this HILIC column could improve separation resolution, and solved the co-elution problem of anthocyanin and non-anthocyanins in one-dimensional RPLC. Consequently, the target anthocyanin and three new alkaloids were isolated from $L$. ruthenicum for the first time.

Stevioside is the major sweet component present in Stevia rebaudiana Bertoni. A 2D-RPLC/HILIC system was established to comprehensively identify steviol glycosides from Stevia rebaudiana, based on an XCharge C18 column in first dimension and an XAmide column in second dimension [38]. 30 fractions were collected in first dimension of Stevia aqueous extract. Then fractions 1-20 were selected for further purification and 13 compounds with high purity were obtained in second dimension.

\subsubsection{Oligosaccharides}

Raffinose family oligosaccharides (RFOs) popularity as food ingredients has 
intensively increased, due to their fermentation effect in the large intestine. These analytes are polar, hydrophilic and highly branched, and thus are poorly retained on RP columns and eluted close to the dead volume. Liu et al. [47] firstly developed a HILIC method for the RFOs analysis, based on a BEH amide column. Nine neutral saccharides in Radix Rehmenniae were simultaneous identified.

Jin et al. [48] reported an efficient method to purify RFOs from Lycopus lucidus Turcz with a homemade zwitterionic HILIC stationary phase (named Click TE-Cys). This column exhibited good hydrophilicity and selectivity in the separation of oligosaccharides, solving the problem of weak retention when using C18 columns. Based on the analysis, three oligosaccharides, including stachyose, verbascose and ajugos, were isolated at semi-preparative scale.

\subsubsection{Steroids}

Steroids are widely distributed in TCMs. Bufadienolides are a type of steroids with cardiotonic, anesthetic, blood pressure-stimulating and antitumor bioactivities $[49,50]$. To systematically separate bufadienolides, an XTerra Prep C18 column and a Click $\beta$-CD column were used to construct an orthogonal 2D-RPLC/HILIC system [51]. The XTerra Prep C18 column was used in the first dimension and 75 fractions from the toad skin extract were prepared in this dimension. After screening for their activities, two active fractions (Fr. 24 and Fr. 29) were selected for further purification in the second dimension using the Click $\beta-\mathrm{CD}$ column. The comparison results showed that compounds in Fr. 24 that almost co-eluted on the RP column were well resolved on the Click-CD column (Fig. 2). This mainly benefits from the different selectivities of these two columns. As a result, seven compounds were obtained with high purity from two active fractions, including four stereoisomers. Recently, a hydrophilic interaction liquid chromatography solid-phase extraction (HILIC-SPE) method was established to isolate amino acid-conjugated bufadienolides and amino acid-unconjugated bufadienolides, which co-eluted on C18 columns [52]. Using this strategy, eight bufadienolides were obtained from one active fraction.

\subsubsection{Phenolic acids}

Phenolic acids (PAs) are the active constituents of Salvia miltiorrhiza. Nonetheless, owing to the existing of multiple ester bonds and unsaturated bonds in the structures, PAs have numerous chemical conversion products. Many of them are so low-abundant that difficult to be separated employing conventional methods. Bi et al. [53] chose an Acchrom XAmide column and a Waters Acquity HSS T3 column to 
establish an offline 2D-HILIC/RPLC method for the separation of PAs in Salvia miltiorrhiza. This method showed high peak capacities (practical peak capacity greater than 2046, and effective peak capacity greater than1130) and good orthogonality (ranging from $69.7 \%$ to $92.8 \%$ ) for all the samples. A total of 265 PAs were characterized with a combination of $2 \mathrm{D}-\mathrm{LC}$ and mass spectrometry (MS). Of these, 196 compounds were discovered from Salvia miltiorrhiza and its related samples.

\subsection{Polar-modified RPLC stationary phases}

\subsubsection{Recent development in polar-modified RPLC stationary phases}

RPLC, the most commonly used mode in LC, has been extensively used in pharmaceutical, biological and environmental analyses, due to high separation efficiency, MS compatibility, and broad analyte coverage. Silica-based conventional C18 phases are currently the most widely used of all the available stationary phases. However, typical drawbacks of conventional RPLC stationary phases include peak tailing of basic compounds probably due to the interaction with unreacted silanols on the silica surface and also dewetting or phase collapse in highly aqueous conditions $[54,55]$. The ameliorations in conventional RP C 18 stationary phases are required.

In addition to the developments in silica synthesis and surface bonding technology for the preparation of conventional RP C18 stationary phases, two types of polar-modified C18 stationary phases that are gaining popularity are polar-embedded and polar-endcapped stationary phases [54]. These phases are modification of the classical C18 stationary phase with the addition of a polar functional group, such as an amide or carbamate group, within the alkyl chain itself (polar-embedded phases), or a polar functional group used as an endcapping agent (polar-endcapped phases). These phases have attracted attention for following reasons: improved peak shape for basic analytes, alternative selectivity, reduced silanol activity, and stability in highly aqueous mobile phases [56-58].

In 2001, O' Gara et al. [59] produced an introductory review on polar-embedded phases. In 2004, Buszewski [60] had published a comprehensive review of polar-embedded, and in particular amide, stationary phases, focusing on their characterization and applications. In 2010, Glennon et al. [61] summarized the development of polar-embedded and polar-endcapped stationary phases, and highlight the range of diverse embedded groups which can be prepared. In recent years, diverse 
polar-embedded and polar-endcapped stationary phases have been reported. For instance, Laemmerhofer et al. [62] introduced a mixed-mode reversed-phase/weak anion-exchange type stationary phases, which consisted of a hydrophobic alkyl chain with polar-embedded groups (thioether and amide functionalities) and a terminal weak anion-exchange-type quinuclidine moiety. This stationary phase showed the considerable flexibility, in particular for peptide separations, benefiting from the distinct separation mechanisms. Sun et al. [63] developed a series of polar-embedded C10 dipeptide stationary phases. These stationary phases showed higher retention for polar and hydrophilic compounds and different selectivity compared to conventional C18 columns. In addition, high column efficiency and good peak shapes for both acidic and basic compounds were obtained. Jiang et al. [64] prepared two stationary phases modified by alkylimidazoliums. Different effects of distributions of polar functional group and octadecyl chain were found to impact the chromatographic properties. Qiu et al. [65] reported the preparation of a polar-embedded C30 stationary phase. The polar carbamate group was generated homogeneously in situ by the catalytic reaction between isocyanate and primary alcohol. This approach offered an effective strategy for modification of silica spheres. After systematic evaluation, the polar-embedded C30 stationary phase exhibited superior shape selectivity. Shi et al. [66] developed a simple method for the synthesis of a reversed-phase packing containing both polar-embedded and polar-endcapped moieties, based on the epoxide addition reaction of 3-glycidoxypropyltrimethoxysilane with 1-octadecanethiol proceeded simultaneously with the reaction of silane coupling onto silica particles. Neutral, acidic and basic analytes were well separated on this column. Furthermore, good stability in $100 \%$ aqueous solution and low activity of residue silanols was observed.

In our group, a polar-copolymerized approach was used to prepare polar-modified RP stationary phases using the horizontal polymerization technique on the surface [67]. Using this method, a representative polar-copolymerized stationary phase (C18HCE) composed of mixed n-octadecyl and chloropropyl (C18-C3C1) was synthesized. Based on the polar-copolymerized approach, n-octadecyl and functional polar groups were facilely copolymerized on the silica surface, featuring a variety of polar-modified stationary phases, such as C18SAX (n-octadecyl and quaternary ammonium) [68], C18WCX (n-octadecyl and carboxyl groups) [69], and C18SCX (n-octadecyl and sulfo groups) [70]. These stationary phases were able to offer 
multiple modes of interaction to analytes in the separation, providing unique separation selectivity.

\subsubsection{Applications of polar-modified RPLC stationary phases in TCMs}

\subsubsection{Alkaloids}

Alkaloids are widely distributed in the plant kingdom, and have received increasing interest, due to their pharmacological activities [71]. For instance, berberine, an isoquinoline alkaloid, is a major active compound in Coptidis Rhizoma (Hunaglian). Berberine and Huanglian have long been used to treat intestinal infections including cholera, acute gastroenteritis, and bacillary dysentery [72]. Alkaloids are still the most important natural products in drug discovery.

To date, the separation and purification of basic solutes is still problematic on most conventional RP C18 columns. Severe peak tailing often occurs even with a small amount of injection [73], and chromatographic performance deteriorates rapidly with increased sample loading in preparative separation [74], which is known as the overloading problem. Purification throughput is small because of low loadability, and the obtained compounds often have unfavorable purities and recoveries.

It has long been recognized that the strong ionic-exchange interactions between positively charged alkaloids and the residual silanols on the surface of silica are the key reason for poor peak shapes and irreversible adsorption [75]. Sometimes, buffer additives are useful for solving the tailing problem, including ion-pairing reagents [76] and inorganic salts [77]. Improved chromatographic performance of alkaloids can often be observed at analytical perspectives, but their practical value for preparative application may be limited, especially for strong bases.

Other ways of managing base tailing include ameliorations of stationary phase chemistry, such as high surface coverage and exhaustive endcapping. In addition, the polar-endcapped and the polar-embedded RPLC phases are gaining interest for the separation of alkaloids [54]. The modified polar group offers the phase additional polarity and thereby helps to maintain a water layer near the silica surface, which prevents shield basic solutes from reaching the residual silanol groups [78]. Sharp and symmetric peak shapes for alkaloids can often be produced on such polar-modified RP phases. Nevertheless, mild tailing peaks of alkaloids still appear, and their practical application in purification remains to be improved.

To solve above problem, a positively charged stationary phase C18 (named 
C18HCE) was synthesized and used to purification of quaternary alkaloids from Corydalis yanhusuo W. T. Wang [67, 79]. As shown in Fig. 3, symmetric peak shapes were observed with the C18HCE column (Fig. 3a) even with high sample loading (Fig. 3b). However, severe peak tailing problems were observed with the other stationary phases (Fig. 3c-j). The good performance for bases on this column could be explained using the multiple-site adsorption theory, in which the ionic repulsion would shield compounds from occupying high-energy sites in C18 deeper layer [80]. Using this method, 80 fractions of Corydalis yanhusuo W. T. were obtained, and then assayed for their ability to activate $\mu$-opioid receptor. Results showed that only one fraction was able to trigger a reproducible and dose-dependent intracellular $\mathrm{Ca}^{2+}$ mobilization [81]. In order to cope with the complexity of the active fraction, an orthogonal IEC $\times$ RPLC system was constructed to purify the active compound in this fraction. The active compound was successfully purified and identified as dehydrocorybulbine (DHCB) by UV, MS, NMR and single X-ray crystallography. Further testing using selective pharmacological compounds and dopamine receptor knockout mice showed that the antinociceptive effect of DHCB was primarily due to its interaction with dopamine D2 receptor [81]. It was found that $\mathrm{DHCB}$ was effective to treat injury-induced neuropathic pain and inflammatory pain and caused no antinociceptive tolerance. The results suggested that DHCB was a different type of analgesic compound and would be a promising lead in pain management.

The water-soluble extract of toad skin, named cinobufacini (Huachansu) injection, has been widely used in the treatment of several cancers in China for many years [82]. Some studies suggest that aqueous extract alkaloids are the major compositions in cinobufacini injections. Zhao et al. [83] established an efficient method to separate basic compounds from toad skin, based on a C18HCE column. The poor retention problem was resolved on the polar-modified C18 column, as well as good resolution was also achieved. Seven compounds were purified from toad skin and five of them were identified as uracil, hypoxanthine, 3-hydroxy- $4 \mathrm{H}$-pyrazolo [4, $5-d]$ pyridazin-7(1H)-one, thymine and bufothionine.

\subsubsection{Other constituents}

Aristolochic acids (AAs), structurally related nitrophenanthrene carboxylic acids, are widely distributed in Aristolochia and Asarum species herbs. AAs are demonstrated to cause severe irreversible renal failure, which could only be cured by renal transplantation [84]. An efficient method was established for the enrichment of 
aristolochic acids, based on a polar-copolymerized stationary phase (named C18SAX) [85]. Aristolochic acids experience both hydrophobic interaction and anion-exchange mechanism on this stationary phase. And thus, C18SAX material-based SPE was developed to enrich aristolochic acids from the Caulis Aristochiae Manshuriensis. The complexity of sample matrices was simplified after the SPE procedure and further preparation and purification of target compounds was conducted on a preparative RP C18 column. Four aristolochic acids, including aristolochic acid I (31.8 mg), II (8.9 mg), IIIa $(6.1 \mathrm{mg})$ and IVa $(4.3 \mathrm{mg})$ were purified with HPLC purities more than $93 \%$.

The cis-trans isomerism is a common phenomenon for acylated anthocyanins. A HPLC method was developed to purify anthocyanin isomers from Lycium ruthenicum Murr. employing a mixed-mode reversed-phase/strong anion-exchange column (named XCharge C8SAX) [86]. This stationary phase exhibited exhibited improved selectivity and column efficiency for the isomers, compared to conventional C18 columns. After mobile phase optimization, optimal separation for the anthocyanin isomers was achieved on the XCharge C8SAX column. As a result, six anthocyanins, including two pairs of cis-trans isomeric anthocyanins, were purified from $L$. ruthenicum and identified.

A conventional C18 column and a polar-copolymerized C18 column (C18HC) were used to construct a 2D-LC method for the purification of polar compounds from Radix isatidis [87]. C18HC along with several commercial columns were tested with a polar fraction collected from the conventional C18 column (Fig. 4). The comparison results demonstrated that $\mathrm{C} 18 \mathrm{HC}$ displayed much better chromatographic retention and resolution. The established 2D-RP/RPLC system showed reasonable orthogonality for polar compounds in Radix isatidis. As a consequence, ten compounds were purified and three of these were identified.

At present, various $\mathrm{C} 18$ stationary phases from different column manufacturers are commercially available. However, similar chromatographic performances are often observed using these phases, because of the identical separation mechanism. 2D-RP/RPLC presents quite a challenge in terms of identifying column combinations that are sufficiently orthogonal. The availability of various polar-modified stationary phases offers a high degree of flexibility in RPLC, which is favorable to the construction of orthogonal 2D-RP/RPLC systems for the separation of TCM components. 


\section{High-efficiency stationary phases for TCMs}

Most TCMs are often prepared from crude plants, which contain numerous chemical components with abundant diversity. These characteristics pose a challenge to the high-efficiency separation of TCMs, due to the lack of powerful analytical techniques. In 2004, Waters revolutionized LC with the introduction of the ACQUITY Ultra high-performance-liquid-chromatography (UHPLC) System. Since then, the UHPLC technique has attracted ever-increasing attention for its high resolution and increased peak capacity. Sub-2 $\mu \mathrm{m}$ porous particles are the heart of the UHPLC system. The use of columns packed with these particles results in fast separation without compromising resolution. When coupled with MS or tandem mass spectrometry (MS/MS), reliable and sensitive detection is achieved. UHPLC-MS is gradually accepted and applied to TCMs. In 2014, Wang et al. [88] published a comprehensive review on the applications of UHPLC-MS in TCM research, highlighting its advantages with characteristic examples. In this section, we tend to give an overview of application UHPLC in TCM separation, focusing on high-efficiency stationary phases (Table 1).

TCMs are multi-component system with chemical compounds mostly unknown, like a "black" system. UHPLC-MS has frequently been used in the separation and characterization of TCMs. Zhu et al. [89] developed an UHPLC-MS method for the characterization of steroidal saponins from Dioscorea zingiberensis $\mathrm{C}$. H. Wright (D. zingiberensis). The extract was separated on a Waters UHPLC Acquity BEH C18 column $(100 \times 2.1 \mathrm{~mm}, 1.7 \mu \mathrm{m})$ within $35 \mathrm{mins}$, and analyzed by MS. Benefiting from the improved separation, a total of thirty-one saponins with five aglycone skeletons, including fourteen new trace saponins, were identified in $D$ zingiberensis.

The pharmacologic mechanisms of TCMs are often hard to be clarified clearly, because of the lack of efficient techniques to screen and identify active compounds. Jia et al. [90] proposed a fast strategy for separation and identification of active components of cancer metastatic chemopreventives from Murraya exotica by UHPLC-MS. After bioactivity investigation, chemical studies of the extracts have been conducted using UHPLC-MS on a Waters Acquity BEH C18 column $(100 \times 2.1$ $\mathrm{mm}, 1.7 \mu \mathrm{m})$. The analysis time was only about half of that of HPLC. After separation, some coumarins were detected in the root and leaf extracts, which were responsible for the inhibition of cancer cell viability and migration. Among them, one novel 
coumarin was separated from the Murraya genus and structurally identified by NMR spectroscopy.

The quality control is essential for ensuring the efficacy and safety of TCMs. The combination of UHPLC-MS fingerprints and multiple component quantification has become a powerful tool to the quality control of TCMs. Zhang et al. [91] developed a UPLC-MS fingerprinting of SiJunZiTang with a Waters Acquity HSS T3 $(2.1 \times 100$ $\mathrm{mm}, 1.8 \mu \mathrm{m}) .66$ compounds including ginsenosides, flavonoids, triterpenoid and coumarins were detected, 58 of them were tentatively identified.

Liu-Wei-Di-Huang-Wan (LWDHW), shown to have clinical efficacy for "nourishing kidney-yin" in TCMs, has been used for thousands of years in China. Wang et al. [92] established an UHPLC method for the comprehensive quantitative determination of the major bioactive markers in LWDHW. In order to achieve efficient separation, several UPLC columns, including the Agilent Zorbax SB-C18 $(100 \mathrm{~mm} \times 2.1 \mathrm{~mm}, 1.8 \mu \mathrm{m})$, the Agilent Zorbax Plus-C18 $(100 \mathrm{~mm} \times 2.1 \mathrm{~mm}, 1.8$ $\mu \mathrm{m})$, and the Agilent Zorbax SB-Aq C18 $(100 \mathrm{~mm} \times 2.1 \mathrm{~mm}, 1.8 \mu \mathrm{m})$, were evaluated. Similar chromatographic performances were observed. Agilent Zorbax SB-C18 column was selected, owing to its good stability in acidic mobile phases. As a result, eleven constituents in LWDHW were simultaneously determined within 10 mins.

UPLC-MS metabolomics has been applied in the assessment of TCMs. Guo et al. [93] established a new strategy used to study the metabolism of crude extract from Ganoderma lucidum using UHPLC-MS. Five representative single compounds (ganoderic acid) were separated on a Waters Acquity HSS T3 column $(2.1 \times 100 \mathrm{~mm}$, $1.8 \mu \mathrm{m}$ ) within 30 mins. A total of 90 metabolites were identified from the bile sample after oral administration of the crude extract.

The use of UHPLC system with sub-2 $\mu$ m porous particle columns is able to realize fast analysis of TCMs. High-efficiency stationary phases have been considered as a potent candidate for TCM separation. However, it is worth mentioning that the separation is almost exclusively performed on RP C18 stationary phases (Table 1). Recently, several polar-modified RP columns, such as Waters Acquity HSS T3 and Acquity BEH Shield RP18, have been applied in this area. More UHPLC stationary phases with different selectivities are expected in the future 


\section{Conclusion}

The separation of TCMs has long been a formidable task, due to the significant complexity in chemical compositions. In recent years, there has been a considerable increase in LC methods for TCMs, based on selective stationary phases. (1) HILIC stationary phases appear to be an alternative choice to conventional $\mathrm{C} 18$ in the separation of TCM components, such as glycosides, oligosaccharides, steroids, and phenolic acids. This is mainly attributed to the distinct separation selectivities. In order to further expand the application of HILIC phases in TCMs, novel HILIC stationary phases with high selectivity and strong hydrophilicity are of importance. (2) Polar-modified stationary phases exhibit superior chromatographic performance for alkaloids, related to the addition of polar groups in the surface. Besides, these phases are able to provide complementary selectivity to conventional $\mathrm{C} 18$ columns, which confers a high degree of flexibility to RPLC methods. (3) 2D-LC, which offers resolution and peak capacity that far exceed that obtained with one-dimensional LC, remains essential in managing the vast complexity of TCMs. The selective stationary phases are of great significance to construct orthogonal 2D-LC systems for TCM separation.

Moreover, high-efficiency separation has become a notable tendency in the analysis of TCMs. UHPLC system with sub-2 $\mathrm{mm}$ particle columns has been widely applied this area. More UHPLC stationary phases with different selectivities are expected in the future. 


\section{Acknowledges}

This work was supported by the External Cooperation Program of BIC, Chinese Academy of Science(121421KYSB20130013), and "Project of National Science Foundation of China 81274077 and 21305138 " 


\section{Reference}

[1] G.J. Dobos, L. Tan, M.H. Cohen, M. McIntyre, R. Bauer, X. Li, A. Bensoussan, Are national quality standards for traditional Chinese herbal medicine sufficient? - Current governmental regulations for traditional Chinese herbal medicine in certain Western countries and China as the Eastern origin country, Complement. Ther. Med., 13 (2005) 183-190.

[2] J. Wan, X. Bai, X. Cai, Y. Rao, Y. Wang, Y. Wang, Chemical differentiation of Da-Cheng-Qi-Tang, a Chinese medicine formula, prepared by traditional and modern decoction methods using UPLC/Q-TOFMS-based metabolomics approach, J. Pharm. Biomed. Anal., 83 (2013) 34-42.

[3] K. Wang, Z. Zhu, L. Yang, Y. Gao, W. Liu, H. Zhang, Y. Chai, Detection, characterization and identification of major constituents in Zhimu-Baihe herb-pair extract by fast high-performance liquid chromatography and time-of-flight mass spectrometry through dynamic adjustment of fragmentor voltage, Rapid Commun. Mass Sp., 25 (2011) 9-19.

[4] A. Zhang, H. Sun, X. Wang, Recent advances in natural products from plants for treatment of liver diseases, Eur. J. Med. Chem., 63 (2013) 570-577.

[5] T.T. Wang, X.H. Jiang, L. Yang, S.H. Wu, pH-gradient counter-current chromatography isolation of natural antioxidant chlorogenic acid from Lonicera japonica Thumb. using an upright coil planet centrifuge with three multi-layer coils connected in series, J. Chromatogr. A, 1180 (2008) 53-58.

[6] Z.L. Gan, Z. Liang, X.S. Chen, X. Wen, Y.X. Wang, M. Li, Y.Y. Ni, Separation and preparation of 6-gingerol from molecular distillation residue of Yunnan ginger rhizomes by high-speed counter-current chromatography and the antioxidant activity of ginger oils in vitro, J. Chromatogr. B, 1011 (2016) 99-107.

[7] H.H. Lv, H.L. Wang, Y.F. He, C.X. Ding, X.Y. Wang, Y.R. Suo, Separation and purification of four oligostilbenes from Iris lactea Pall. var. chinensis (Fisch.) Koidz by high-speed counter-current chromatography, J. Chromatogr. B, 988 (2015) 127-134.

[8] E.L. Liu, Q.S. Li, Separation and purification of total organic acids from immature flower of Lonicera japonica by macroporous resin, Chinese Traditional and Herbal Drugs, 37 (2006) 1792-1795.

[9] J. Feng, Y. Xiao, Z. Guo, D. Yu, Y. Jin, X. Liang, Purification of compounds from Lignum Dalbergia Odorifera using two-dimensional preparative chromatography with Click oligo (ethylene glycol) and C18 column, J. Sep. Sci., 34 (2011) 299-307.

[10] Y.P. Wang, X.Y. Xue, Y.S. Xiao, F.F. Zhang, Q. Xu, X.M. Liang, Purification and preparation of compounds from an extract of Scutellaria barbata D. Don using preparative parallel high performance liquid chromatography, J. Sep. Sci., 31 (2008) 1669-1676.

[11] J. Zhang, Y. Jin, Y.F. Liu, Y.S. Mao, J.T. Feng, X.Y. Xue, X.L. Zhang, X.M. Liang, Purification of alkaloids from Corydalis yanhusuo W. T. Wang using preparative 2-D HPLC, J. 
Sep. Sci., 32 (2009) 1401-1406.

[12] M.P. La, F. Zhang, S.H. Gao, X.W. Liu, Z.J. Wu, L.N. Sun, X. Tao, W.S. Chen, Constituent analysis and quality control of Lamiophlomis rotata by LC-TOF/MS and HPLC-UV, J. Pharm. Biomed. Anal., 102 (2015) 366-376.

[13] X. Qiao, G. Ye, C. Liu, Z. Zhang, Q. Tu, J. Dong, Y. Li, D. Guo, M. Ye, Chemical analysis of Eriocaulon buergerianum and adulterating species by high-performance liquid chromatography with diode array detection and electrospray ionization tandem mass spectrometry, J. Pharm. Biomed. Anal., 57 (2012) 133-142.

[14] Y. Shen, C. Han, X. Chen, X. Hou, Z. Long, Simultaneous determination of three Curcuminoids in Curcuma wenyujin Y.H.chen et C.Ling. by liquid chromatography-tandem mass spectrometry combined with pressurized liquid extraction, J. Pharm. Biomed. Anal., $81-82$ (2013) 146-150.

[15] Y.R. Li, K. Yang, Q.Q. Shi, B.W. Liu, Y. Jin, X.S. Liu, Z.L. Jiang, L.J. Luan, Y.J. Wu, Development of a method using high-performance liquid chromatographic fingerprint and multi-ingredients quantitative analysis for the quality control of Yangxinshi Pian, J. Sep. Sci., 38 (2015) 2989-2994.

[16] X.Y. Guan, H.F. Li, W.Z. Yang, C.H. Lin, C. Sun, B.R. Wang, D.A. Guo, M. Ye, HPLC-DAD-MSn analysis and HPLC quantitation of chemical constituents in Xian-ling-gu-bao capsules, J. Pharm. Biomed. Anal., 55 (2011) 923-933.

[17] J. Zhang, L.S. Wang, J.M. Gao, Y.J. Xu, L.F. Li, C.H. Li, Rapid Separation and Identification of Anthocyanins from Flowers of Viola yedoensis and V. prionantha by High-performance Liquid Chromatography-Photodiode Array Detection-Electrospray Ionisation Mass Spectrometry, Phytochem. Anal., 23 (2012) 16-22.

[18] H.F. Li, X.Y. Guan, M. Ye, C. Xiang, C.H. Lin, C. Sun, D.A. Guo, Qualitative and quantitative analyses of Epimedium wushanense by high-performance liquid chromatography coupled with diode array detection and electrospray ionization tandem mass spectrometry, J. Sep. Sci., 34 (2011) 1437-1446.

[19] M. Gilar, P. Olivova, A.E. Daly, J.C. Gebler, Orthogonality of separation in two-dimensional liquid chromatography, Anal. Chem., 77 (2005) 6426-6434.

[20] D.R. Stoll, X. Li, X. Wang, P.W. Carr, S.E.G. Porter, S.C. Rutan, Fast, comprehensive two-dimensional liquid chromatography, J. Chromatogr. A, 1168 (2007) 3-43.

[21] H.M. Zhang, S.L. Li, H. Zhang, Y. Wang, Z.L. Zhao, S.L. Chen, H.X. Xu, Holistic quality evaluation of commercial white and red ginseng using a UPLC-QTOF-MS/MS-based metabolomics approach, J. Pharm. Biomed. Anal., 62 (2012) 258-273.

[22] X. Wang, Y. Wu, Q. Wu, Y. Qian, W. Yue, Q. Liang, Ultra-High Performance Liquid Chromatography-Tandem Mass Spectrometry for Rapid Analysis of Seven Phenolic Compounds of Sparganii Rhizoma, Acta Chromatogr., 27 (2015) 755-766.

[23] X. Zhang, L. Liu, L. Zhu, Y. Bai, Q. Mao, S. Li, S. Chen, H. Xu, A high performance liquid 
chromatography fingerprinting and ultra high performance liquid chromatography coupled with quadrupole time-of-flight mass spectrometry chemical profiling approach to rapidly find characteristic chemical markers for quality evaluation of dispensing granules, a case study on Chuanxiong Rhizoma, J. Pharm. Biomed. Anal., 88 (2014) 391-400.

[24] Q. Zhang, C.-h. Wang, Y.-m. Ma, E.-y. Zhu, Z.-t. Wang, UPLC-ESI/MS determination of 17 active constituents in two categorized formulas of traditional Chinese medicine, Sanhuang Xiexin Tang and Fuzi Xiexin Tang: application in comparing the differences in decoctions and macerations, Biomed. Chromatogr., 27 (2013) 1079-1088.

[25] A.J. Alpert, Hydroophilic-interaction chromatography for the separation of peptides, nucleic-acids and other polar compounds, J. Chromatogr., 499 (1990) 177-196.

[26] V.V. Tolstikov, O. Fiehn, Analysis of highly polar compounds of plant origin: Combination of hydrophilic interaction chromatography and electrospray ion trap mass spectrometry, Anal. Biochem., 301 (2002) 298-307.

[27] T. Ikegami, K. Tomomatsu, H. Takubo, K. Horie, N. Tanaka, Separation efficiencies in hydrophilic interaction chromatography, J. Chromatogr. A, 1184 (2008) 474-503.

[28] A.J. Shen, Z.M. Guo, X.M. Cai, X.Y. Xue, X.M. Liang, Preparation and chromatographic evaluation of a cysteine-bonded zwitterionic hydrophilic interaction liquid chromatography stationary phase, J. Chromatogr. A, 1228 (2012) 175-182.

[29] P. Hemstrom, K. Irgum, Hydrophilic interaction chromatography, J. Sep. Sci., 29 (2006) 1784-1821.

[30] H.D. Qiu, X.J. Liang, M. Sun, S.X. Jiang, Development of silica-based stationary phases for high-performance liquid chromatography, Anal. Bioanal. Chem., 399 (2011) 3307-3322.

[31] A.J. Shen, Z.M. Guo, X.M. Liang, Development and Application of Hydrophilic Interaction Liquid Chromatographic Stationary Phases, Prog. Chem., 26 (2014) 10-18.

[32] S.J. Liu, H.X. Xu, J.J. Yu, D.Y. Li, M.Y. Li, X.Q. Qiao, X.Y. Qin, H.Y. Yan, Novel imidazolium-embedded N,N-dimethylaminopropyl-functionalized silica-based stationary phase for hydrophilic interaction/reversed-phase mixed-mode chromatography, Anal. Bioanal. Chem., 407 (2015) 8989-8997.

[33] T. Yong, F. Wu, H.B. Xiao, B.S. Wan, Silica modified with a thiourea derivative as a new stationary phase for hydrophilic interaction liquid chromatography, J. Sep. Sci., 38 (2015) 3852-3861.

[34] S.J. Wu, X.L. Li, F.F. Zhang, G. Jiang, X.M. Liang, B.C. Yang, An arginine-functionalized stationary phase for hydrophilic interaction liquid chromatography, Analyst, 140 (2015) 3921-3924.

[35] S.L. Ji, Y. Zheng, F.F. Zhang, X.M. Liang, B.C. Yang, A polyvinyl alcohol-coated silica gel stationary phase for hydrophilic interaction chromatography, Analyst, 140 (2015) 6250-6253.

[36] D.P. Yu, A.J. Shen, Z.M. Guo, Y.K. Yan, J.Y. Yan, G.W. Jin, X.M. Liang, A controlled thiol-initiated surface polymerization strategy for the preparation of hydrophilic polymer 
stationary phases, Chem. Commun., 51 (2015) 14778-14780.

[37] G.W. Jin, D.P. Yu, Z.M. Guo, D. Yang, H.T. Zhang, A.J. Shen, J.Y. Yan, X.M. Liang, Preparation of glyco-silica materials via thiol-ene click chemistry for adsorption and separation, Rsc Adv., 6 (2016) 8584-8587.

[38] Q. Fu, Z.M. Guo, X.L. Zhang, Y.F. Liu, X.M. Liang, Comprehensive characterization of Stevia Rebaudiana using two-dimensional reversed-phase liquid chromatography/hydrophilic interaction liquid chromatography, J. Sep. Sci., 35 (2012) 1821-1827.

[39] X.J. Guo, X.L. Zhang, J.T. Feng, Z.M. Guo, Y.S. Xiao, X.M. Liang, Purification of saponins from leaves of Panax notoginseng using preparative two-dimensional reversed-phase liquid chromatography/hydrophilic interaction chromatography, Anal. Bioanal. Chem., 405 (2013) 3413-3421.

[40] W.Z. Yang, W. Si, J.X. Zhang, M. Yang, H.Q. Pan, J. Wu, S. Qiu, C.L. Yao, J.J. Hou, W.Y. Wu, D.A. Guo, Selective and comprehensive characterization of the quinochalcone C-glycoside homologs in Carthamus tinctorius L. by offline comprehensive two-dimensional liquid chromatography/LTQ-Orbitrap MS coupled with versatile data mining strategies, Rsc Adv., 6 (2016) 495-506.

[41] A. Osbourn, R.J.M. Goss, R.A. Field, The saponins - polar isoprenoids with important and diverse biological activities, Nat. Prod. Rep., 28 (2011) 1261-1268.

[42] J.M. Augustin, V. Kuzina, S.B. Andersen, S. Bak, Molecular activities, biosynthesis and evolution of triterpenoid saponins, Phytochemistry, 72 (2011) 435-457.

[43] C. Bachran, S. Bachran, M. Sutherland, D. Bachran, H. Fuchs, Saponins in tumor therapy, Mini-Rev. Med. Chem., 8 (2008) 575-584.

[44] Q.Q. Xing, T. Liang, G.B. Shen, X.L. Wang, Y. Jin, X.M. Liang, Comprehensive HILIC x RPLC with mass spectrometry detection for the analysis of saponins in Panax notoginseng, Analyst, 137 (2012) 2239-2249.

[45] X.J. Guo, X.L. Zhang, Z.M. Guo, Y.F. Liu, A.J. Shen, G.W. Jin, X.M. Liang, Hydrophilic interaction chromatography for selective separation of isomeric saponins, J. Chromatogr. A, 1325 (2014) 121-128.

[46] H.L. Jin, J.Q. Zhao, W.J. Zhou, A.J. Shen, F. Yang, Y.F. Liu, Z.M. Guo, X.L. Zhang, Y.D. Tao, X.J. Peng, X.M. Liang, Preparative separation of a challenging anthocyanin from Lycium ruthenicum Murr. by two-dimensional reversed-phase liquid chromatography/hydrophilic interaction chromatography, Rsc Adv., 5 (2015) 62134-62141.

[47] Z.R. Liu, Z.Y. Lou, X. Ding, X. Li, Y.P. Qi, Z.Y. Zhu, Y.F. Chai, Global characterization of neutral saccharides in crude and processed Radix Rehmanniae by hydrophilic interaction liquid chromatography tandem electrospray ionization time-of-flight mass spectrometry, Food Chem., 141 (2013) 2833-2840.

[48] T. Liang, Q. Fu, F.B. Li, W. Zhou, H.X. Xin, H. Wang, Y. Jin, X.M. Liang, Hydrophilic interaction liquid chromatography for the separation, purification, and quantification of raffinose 
family oligosaccharides from Lycopus lucidus Turcz, J. Sep. Sci., 38 (2015) 2607-2613.

[49] G.A. Cunha Filho, C.A. Schwartz, I.S. Resck, M.M. Murta, S.S. Lemos, M.S. Castro, C. Kyaw, O.R. Pires, Jr., J.R.S. Leite, C. Bloch, Jr., E.F. Schwartz, Antimicrobial activity of the bufadienolides marinobufagin and telocinobufagin isolated as major components from skin secretion of the toad Bufo rubescens, Toxicon : official journal of the International Society on Toxinology, 45 (2005) 777-782.

[50] W. Schoner, G. Scheiner-Bobis, Endogenous and exogenous cardiac glycosides: their roles in hypertension, salt metabolism, and cell growth, Am. J. Physiol-Cell Ph., 293 (2007) C509-C536.

[51] Y.F. Liu, J.T. Feng, Y.S. Xiao, Z.M. Guo, J. Zhang, X.Y. Xue, J. Ding, X.L. Zhang, X.M. Liang, Purification of active bufadienolides from toad skin by preparative reversed-phase liquid chromatography coupled with hydrophilic interaction chromatography, J. Sep. Sci., 33 (2010) 1487-1494.

[52] X.L. Li, Y.F. Liu, A.J. Shen, C.R. Wang, J.Y. Yan, W.J. Zhao, X.M. Liang, Efficient purification of active bufadienolides by a class separation method based on hydrophilic solid-phase extraction and reversed-phase high performance liquid chromatography, J. Pharm. Biomed. Anal., 97 (2014) 54-64.

[53] W.Y. Sun, L. Tong, J.Z. Miao, J.Y. Huang, D.X. Li, Y.F. Li, H.T. Xiao, H. Sun, K.S. Bi, Separation and analysis of phenolic acids from Salvia miltiorrhiza and its related preparations by off-line two-dimensional hydrophilic interaction chromatography $\mathrm{x}$ reversed-phase liquid chromatography coupled with ion trap time-of-flight mass spectrometry, J. Chromatogr. A, 1431 (2016) 79-88.

[54] J. Layne, Characterization and comparison of the chromatographic performance of conventional, polar-embedded, and polar-endcapped reversed-phase liquid chromatography stationary phases, J. Chromatogr. A, 957 (2002) 149-164.

[55] J.L. Rafferty, J.I. Siepmann, M.R. Schure, Molecular-level comparison of alkylsilane and polar-embedded reversed-phase liquid chromatography systems, Anal. Chem., 80 (2008) 6214-6221.

[56] C.R. Silva, S. Bachmann, R.R. Schefer, K. Albert, I. Jardim, C. Airoldi, Preparation of a new C-18 stationary phase containing embedded urea groups for use in high-performance liquid chromatography, J. Chromatogr. A, 948 (2002) 85-95.

[57] S. Bocian, P. Vajda, A. Felinger, B. Buszewski, Solvent excess adsorption on the stationary phases for reversed-phase liquid chromatography with polar functional groups, J. Chromatogr. A, 1204 (2008) 35-41.

[58] L.L. Jing, R. Jiang, P. Liu, P.A. Wang, T.Y. Shi, X.L. Sun, Selectivity differences between alkyl and polar-modified alkyl phases in reversed phase high performance liquid chromatography, J. Sep. Sci., 32 (2009) 212-220.

[59] J.E. O'Gara, D.P. Walsh, C.H. Phoebe, B.A. Alden, I.S.P. Bouvier, P.C. Iraneta, M. Capparella, T.H. Walter, Embedded-polar-group bonded phases for high performance liquid chromatography, 
Lc Gc N. Am., 19 (2001) 632-+.

[60] B. Buszewski, T. Welerowicz, Stationary phases with special structural properties for high-throughput separation techniques: Preparation, characterization and applications, Comb. Chem. High T. Scr., 7 (2004) 291-312.

[61] G.P. O'Sullivan, N.M. Scully, J.D. Glennon, Polar-embedded and polar-endcapped statioanry phases for LC, Anal. Lett., 43 (2010) 1609-1629.

[62] M. Laemmerhofer, R. Nogueira, W. Lindner, Multi-modal applicability of a reversed-phase/weak-anion exchange material in reversed-phase, anion-exchange, ion-exclusion, hydrophilic interaction and hydrophobic interaction chromatography modes, Anal. Bioanal. Chem., 400 (2011) 2517-2530.

[63] H.B. Wang, L. Chen, X.L. Tang, Y.Y. Jia, G.Q. Li, X.L. Sun, A.D. Wen, Synthesis and characterization of novel polar-embedded silica stationary phases for use in reversed-phase high-performance liquid chromatography, J. Chromatogr. A, 1271 (2013) 153-162.

[64] M.L. Zhang, J. Chen, T.N. Gu, H.D. Qiu, S.X. Jiang, Novel imidazolium-embedded and imidazolium-spaced octadecyl stationary phases for reversed phase liquid chromatography, Talanta, 126 (2014) 177-184.

[65] M.L. Zhang, W.P. Mai, L. Zhao, Y. Guo, H.D. Qiu, A polar-embedded C30 stationary phase: Preparation and evaluation, J. Chromatogr. A, 1388 (2015) 133-140.

[66] H.Y. Liu, Z.Y. Li, D. Liu, Y.W. Xue, Z.G. Shi, A simple method for the synthesis of a polar-embedded and polar-endcapped reversed-phase chromatographic packing with low activity of residue silanols, J. Chromatogr. A, 1443 (2016) 175-180.

[67] Z.M. Guo, C.R. Wang, T. Liang, X.M. Liang, Polar-copolymerized approach based on horizontal polymerization on silica surface for preparation of polar-modified stationary phases, $\mathrm{J}$. Chromatogr. A, 1217 (2010) 4555-4560.

[68] S.Y. Wei, W.X. Yao, W.Y. Ji, J.Q. Wei, S.Q. Peng, Qualitative and quantitative analysis of anthraquinones in rhubarbs by high performance liquid chromatography with diode array detector and mass spectrometry, Food Chem., 141 (2013) 1710-1715.

[69] X.M. Cai, Z.M. Guo, X.Y. Xue, J.Y. Xu, X.L. Zhang, X.M. Liang, Two-dimensional liquid chromatography separation of peptides using reversed-phase/weak cation-exchange mixed-mode column in first dimension, J. Chromatogr. A, 1228 (2012) 242-249.

[70] X.L. Li, Z.M. Guo, Q.Y. Sheng, X.Y. Xue, X.M. Liang, Sequential elution of multiply and singly phosphorylated peptides with polar-copolymerized mixed-mode RP18/SCX material, Analyst, 137 (2012) 2774-2776.

[71] G.A. Cordell, M.L. Quinn-Beattie, N.R. Farnsworth, The potential of alkaloids in drug discovery, Phytother. Res., 15 (2001) 183-205.

[72] J. Tang, Y.B. Feng, S. Tsao, N. Wang, R. Curtain, Y.W. Wang, Berberine and Coptidis Rhizoma as novel antineoplastic agents: A review of traditional use and biomedical investigations, J. Ethnopharmacol., 126 (2009) 5-17. 
[73] J. Samuelsson, A. Franz, B.J. Stanley, T. Fornstedt, Thermodynamic characterization of separations on alkaline-stable silica-based C18 columns: Why basic solutes may have better capacity and peak performance at higher pH, J. Chromatogr. A, 1163 (2007) 177-189.

[74] D.V. McCalley, The challenges of the analysis of basic compounds by high performance liquid chromatography: Some possible approaches for improved separations, J. Chromatogr. A, 1217 (2010) 858-880.

[75] P.J. Twitchett, A.C. Moffat, High-pressure liquid-chromatography of drugs-Evaluation of an octanecylsilane stationary phase, J. Chromatogr., 111 (1975) 149-157.

[76] T. Mroczek, K. Glowniak, A. Wlaszczyk, Simultaneous determination of N-oxides and free bases of pyrrolizidine alkaloids by canon-exchange solid-phase extraction and ion-pair high-performance liquid chromatography, J. Chromatogr. A, 949 (2002) 249-262.

[77] X.X. Cheng, D.M. Wang, L. Jiang, D.P. Yang, Simultaneous determination of eight bioactive alkaloids in Corydalis saxicola by high-performance liquid chromatography coupled with diode array detection, Phytochem. Anal., 19 (2008) 420-428.

[78] J. Horak, W. Lindner, Contribution of sulfonyl-aromatic and sulfonic acid-aromatic interactions in novel sulfonyl/sulfonic acid-embedded reversed phase materials, J. Chromatogr. A, 1191 (2008) 141-156.

[79] C.R. Wang, Z.M. Guo, J. Zhang, J. Zeng, X.L. Zhang, X.M. Liang, High-performance purification of quaternary alkaloids from Corydalis yanhusuo W. T. Wang using a new polar-copolymerized stationary phase, J. Sep. Sci., 34 (2011) 53-58.

[80] C.R. Wang, Z.M. Guo, Z. Long, X.L. Zhang, X.M. Liang, Overloading study of basic compounds with a positively charged C18 column in liquid chromatography, J. Chromatogr. A, 1281 (2013) 60-66.

[81] Y. Zhang, C.R. Wang, L. Wang, G.S. Parks, X.L. Zhang, Z.M. Guo, Y.X. Ke, K.W. Li, M.K. Kim, B. Vo, E. Borrelli, G.B. Ge, L. Yang, Z.W. Wang, M.J. Garcia-Fuster, Z.D. Luo, X.M. Liang, O. Civelli, A Novel Analgesic Isolated from a Traditional Chinese Medicine, Curr. Biol., 24 (2014) 117-123.

[82] F.H. Qi, A.Y. Li, H. Lv, L. Zhao, J.J. Li, B. Gao, W. Tang, Apoptosis-inducing effect of cinobufacini, Bufo bufo gargarizans Cantor skin extract, on human hepatoma cell line BEL-7402, Drug discoveries \& therapeutics, 2 (2008) 339-343.

[83] X.L. Li, R.Q. Huang, Y.F. Liu, H.L. Jin, H.H. Wan, J.Q. Zhao, W.J. Zhao, X.M. Liang, Efficient purification of low molecular weight nitrogen polar compounds from the skin of Bufo bufo gargarizans Cantor by reversed-phase high performance liquid chromatography with a polar-copolymerized C18 stationary phase, Anal. Methods-Uk, 6 (2014) 5183-5190.

[84] V.M. Arlt, M. Stiborova, H.H. Schmeiser, Aristolochic acid as a probable human cancer hazard in herbal remedies: a review, Mutagenesis, 17 (2002) 265-277.

[85] J. Wei, Z. Guo, P. Zhang, F. Zhang, B. Yang, X. Liang, A new reversed-phase/strong anion-exchange mixed-mode stationary phase based on polar-copolymerized approach and its 
application in the enrichment of aristolochic acids, J. Chromatogr. A, 1246 (2012) 129-136.

[86] H. Jin, Y. Liu, Z. Guo, F. Yang, J. Wang, X. Li, X. Peng, X. Lang, High-Performance Liquid Chromatography Separation of cis-trans Anthocyanin Isomers from Wild Lycium ruthenicum Murr. Employing a Mixed-Mode Reversed-Phase/Strong Anion-Exchange Stationary Phase, J. Agric. Food. Chem., 63 (2015) 500-508.

[87] J. Zeng, Z.M. Guo, Y.S. Xiao, C. Wang, X.L. Zhang, X.M. Liang, Purification of polar compounds from Radix isatidis using conventional C18 column coupled with polar-copolymerized C18 column, J. Sep. Sci., 33 (2010) 3341-3346.

[88] X.J. Wang, A.H. Zhang, G.L. Yan, Y. Han, H. Sun, UHPLC-MS for the analytical characterization of traditional Chinese medicines, Trac-Trend Anal. Chem., 63 (2014) 180-187.

[89] J.B. Zhu, X.J. Guo, S.P. Fu, X.L. Zhang, X.M. Liang, Characterization of steroidal saponins in crude extracts from Dioscorea zingiberensis C. H. Wright by ultra-performance liquid chromatography/electrospray ionization quadrupole time-of-flight tandem mass spectrometry, J. Pharm. Biomed. Anal., 53 (2010) 462-474.

[90] Z. Jiang, J. Yang, Y. Pang, X. Yang, S. Yu, L. Jia, Bioactivity-guided fast screen and identification of cancer metastasis chemopreventive components from raw extracts of Murraya exotica, J. Pharm. Biomed. Anal., 107 (2015) 341-345.

[91] Y.Y. Wang, S. He, X.C. Cheng, Y.X. Lu, Y.P. Zou, Q.L. Zhang, UPLC-Q-TOF-MS/MS fingerprinting of Traditional Chinese Formula SiJunZiTang, J. Pharm. Biomed. Anal., 80 (2013) 24-33.

[92] Y.X. Qiu, J.H. Huang, X.M. Jiang, Y. Chen, Y. Liu, R. Zeng, N. Shehla, Q. Liu, D.F. Liao, D.A. Guo, Y.Z. Liang, W. Wang, Quantitative and qualitative determination of LiuweiDihuang preparations by ultra high performance liquid chromatography in dual-wavelength fingerprinting mode and random forest, J. Sep. Sci., 38 (2015) 3720-3726.

[93] C.R. Cheng, M. Yang, K. Yu, S.H. Guan, X.H. Wu, W.Y. Wu, Y. Sun, C. Li, J. Ding, D.A. Guo, Metabolite identification of crude extract from Ganoderma lucidum in rats using ultra-performance liquid chromatography-quadrupole time-of-flight mass spectrometry, J. Chromatogr. B, 941 (2013) 90-99.

[94] H.Q. Pan, W.Z. Yang, Y.B. Zhang, M. Yang, R.H. Feng, W.Y. Wu, D.A. Guo, An integrated strategy for the systematic characterization and discovery of new indole alkaloids from Uncaria rhynchophylla by UHPLC/DAD/LTQ-Orbitrap-MS, Anal. Bioanal. Chem., 407 (2015) 6057-6070. [95] Z. Jiang, J. Yang, Y.Q. Pang, X.T. Yang, S.H. Yu, L. Jia, Bioactivity-guided fast screen and identification of cancer metastasis chemopreventive components from raw extracts of Murraya exotica, J. Pharm. Biomed. Anal., 107 (2015) 341-345.

[96] M. Zhu, J.A. Duan, Y.P. Tang, J.M. Guo, E.X. Shang, Z.H. Zhu, Identification of Chemical Constituents in SiWu Decoction by UHPLC-DAD-TOF/MS, Acta Chromatogr., 26 (2014) 517-537.

[97] A.H. Ge, Y. Bai, J. Li, J. Liu, J. He, E.W. Liu, P. Zhang, B.L. Zhang, X.M. Gao, Y.X. Chang, 
An activity-integrated strategy involving ultra-high-performance liquid chromatography/quadrupole-time-of-flight mass spectrometry and fraction collector for rapid screening and characterization of the alpha-glucosidase inhibitors in Coptis chinensis Franch. (Huanglian), J. Pharm. Biomed. Anal., 100 (2014) 79-87.

[98] H.W. Du, X.L. Zhao, A.H. Zhang, L. Yao, Y.Y. Zhang, Rapid Separation, Identification and Analysis of Astragalus membranaceus Fisch Using Liquid Chromatography-Tandem Mass Spectrometry, J. Chromatogr. Sci., 52 (2014) 226-231.

[99] M. Qi, A.Z. Xiong, F. Geng, L. Yang, Z.T. Wang, A novel strategy for target profiling analysis of bioactive phenylethanoid glycosides in Plantago medicinal plants using ultra-performance liquid chromatography coupled with tandem quadrupole mass spectrometry, J. Sep. Sci., 35 (2012) 1470-1478.

[100] Y.F. Liu, Y.S. Xiao, X.Y. Xue, X.L. Zhang, X.M. Liang, Systematic screening and characterization of novel bufadienolides from toad skin using ultra-performance liquid chromatography/electrospray ionization quadrupole time-of-flight mass spectrometry, Rapid Commun. Mass Sp., 24 (2010) 667-678.

[101] G.L. Yan, H. Sun, W.J. Sun, L. Zhao, X.C. Meng, X.J. Wang, Rapid and global detection and characterization of aconitum alkaloids in Yin Chen Si Ni Tang, a traditional Chinese medical formula, by ultra performance liquid chromatography-high resolution mass spectrometry and automated data analysis, J. Pharm. Biomed. Anal., 53 (2010) 421-431.

[102] Y. Qi, S.Z. Li, Z.F. Pi, F.R. Song, N. Lin, S. Liu, Z.Q. Liu, Chemical profiling of Wu-tou decoction by UPLC-Q-TOF-MS, Talanta, 118 (2014) 21-29.

[103] T.B. Zhang, R.Q. Yue, J. Xu, H.M. Ho, D.L. Ma, C.H. Leung, S.L. Chau, Z.Z. Zhao, H.B. Chen, Q.B. Han, Comprehensive quantitative analysis of Shuang-Huang-Lian oral liquid using UHPLC-Q-TOF-MS and HPLC-ELSD, J. Pharm. Biomed. Anal., 102 (2015) 1-8.

[104] D.M. Xie, G.X. Liu, F. Xu, M.Y. Shang, Z.W. Zhang, X. Wang, S.Q. Cai, Qualitative and quantitative analysis of dodecatetraenamides A, B in Asari Radix et Rhizoma, China journal of Chinese materia medica, 40 (2015) 691-699.

[105] G.Y. Ding, Y. Nie, Y.Y. Hou, Z.H. Liu, A.N. Liu, J.M. Peng, M. Jiang, G. Bai, An integrated strategy of marker ingredients searching and near infrared spectroscopy rapid evaluation for the quality control of Chinese eaglewood, J. Pharm. Biomed. Anal., 114 (2015) 462-470.

[106] J.Y. An, S.H. Wang, Y.P. Li, M.X. Zhou, C. Liu, X.F. Zhang, X.J. Li, Quantitative Determination of Six Active Ingredients in Shenqi Yiqi Guben Tablet by UPLC-MS, Chinese Journal of Experimental Traditional Medical Formulae, 21 (2015) 99-102.

[107] X.L. Cheng, L.W. Qi, Q. Wang, X.G. Liu, B. Boubertakh, J.Y. Wan, E.H. Liu, P. Li, Highly efficient sample preparation and quantification of constituents from traditional Chinese herbal medicines using matrix solid-phase dispersion extraction and UPLC-MS/MS, Analyst, 138 (2013) 2279-2288.

[108] Y. Zhou, N. Li, F.F.K. Choi, C.F. Qiao, J.Z. Song, S.L. Li, X. Liu, Z.W. Cai, P.P. Fu, G. Lin, 
H.X. Xu, A new approach for simultaneous screening and quantification of toxic pyrrolizidine alkaloids in some potential pyrrolizidine alkaloid-containing plants by using ultra performance liquid chromatography-tandem quadrupole mass spectrometry, Anal. Chim. Acta, 681 (2010) 33-40.

[109] K.Y. Li, Y.P. Fan, H. Wang, Q. Fu, Y. Jin, X.M. Liang, Qualitative and quantitative analysis of an alkaloid fraction from Piper longum L. using ultra-high performance liquid chromatography-diode array detector-electrospray ionization mass spectrometry, J. Pharm. Biomed. Anal., 109 (2015) 28-35.

[110] W.P. Deng, T.T. Xu, M. Yang, Y. Cui, D.A. Guo, Improved Chromatographic Fingerprinting Combined with Multi-components Quantitative Analysis for Quality Evaluation of Penthorum chinense by UHPLC-DAD, Nat Prod. Commun., 10 (2015) 71-76.

[111] S.J. Zhou, J.L. Cao, F. Qiu, W.J. Kong, S.H. Yang, M.H. Yang, Simultaneous Determination of Five Bioactive Components in Radix Glycyrrhizae by Pressurised Liquid Extraction Combined with UPLC-PDA and UPLC/ESI-QTOF-MS Confirmation, Phytochem. Anal., 24 (2013) 527-533.

[112] C.S. Xue, A.H. Zhang, H. Sun, Y. Han, D. Zou, Y.Y. Wang, X.H. Wu, X.J. Wang, An improved ultra-performance liquid chromatography-electrospray ionization/quadrupole-time-of-flight high-definition mass spectrometry method for determining ingredients of herbal Fructus corni in blood samples, Pharmacogn. Mag., 10 (2014) 422-429.

[113] M.S. Xiao, H.Y. Chen, Z.F. Shi, Y.F. Feng, W. Rui, Rapid and reliable method for analysis of raw and honey-processed astragalus by UPLC/ESI-Q-TOF-MS using HSS T3 columns, Anal. Methods-Uk, 6 (2014) 8045-8054.

[114] Q.W. Yin, P. Wang, A.H. Zhang, H. Sun, X.H. Wu, X.J. Wang, Ultra-performance LC-ESI/quadrupole-TOF MS for rapid analysis of chemical constituents of Shaoyao-Gancao decoction, J. Sep. Sci., 36 (2013) 1238-1246.

[115] W. Si, W.Z. Yang, D.A. Guo, J. Wu, J.X. Zhang, S. Qiu, C.L. Yao, Y.J. Cui, W.Y. Wu, Selective ion monitoring of quinochalcone C-glycoside markers for the simultaneous identification of Carthamus tinctorius L. in eleven Chinese patent medicines by UHPLC/QTOF MS, J. Pharm. Biomed. Anal., 117 (2016) 510-521.

[116] H.Y. Qiao, W.L. Zhu, R. Luo, Z.H. Ke, X.F. Hao, X. Ke, Z.G. Wu, Z.R. Zhang, UPLC fingerprint and components identification of Songling Xuemaikang capsules by LC-MS/MS, West China Journal of Pharmaceutical Sciences, 28 (2013) 80-82.

[117] M.H. Liu, X. Tong, J.X. Wang, W. Zou, H. Cao, W.W. Su, Rapid separation and identification of multiple constituents in traditional Chinese medicine formula Shenqi Fuzheng Injection by ultra-fast liquid chromatography combined with quadrupole-time-of-flight mass spectrometry, J. Pharm. Biomed. Anal., 74 (2013) 141-155.

[118] Q.Y. Li, R.M. Wang, Determination of saponins in Wenxin granules by ASE - UPLC, Chinese Journal of Pharmaceutical Analysis, 35 (2015) 528-531.

[119] F.R. Wang, Y. Ai, Y. Wu, W. Ma, Q.X. Bian, D.Y.W. Lee, R.H. Dai, Systematic chemical 
profiling of a multicomponent Chinese herbal formula Huo Luo Xiao Ling Dan by ultra high performance liquid chromatography coupled with electrospray ionization quadrupole time-of-flight mass spectrometry, J. Sep. Sci., 38 (2015) 917-924.

[120] M. Zhao, L.Y. Du, J.H. Tao, D.W. Qian, J.M. Guo, S. Jiang, E.X. Shang, J.A. Duan, C. Wu, Ultra-performance liquid chromatography coupled with quadrupole time-of-flight mass spectrometry for rapid analysis of the metabolites of morroniside produced by human intestinal bacteria, J. Chromatogr. B, 976 (2015) 61-67.

[121] P.Y. Hou, Y. Zeng, B.J. Ma, X.F. Wang, Z.Z. Liu, L. Li, K.K. Qu, K.S. Bi, X.H. Chen, A fast, sensitive, and high-throughput method for the simultaneous quantitation of three ellagitannins from Euphorbiae pekinensis Radix in rat plasma by ultra-HPLC-MS/MS, J. Sep. Sci., 36 (2013) 2544-2551. 


\section{Figure caption}

Fig. 1. HPLC chromatograms of the isomeric saponins in HILIC mode on (A) AtlantisHILIC Silica column $(150 \mathrm{~mm} \times 4.6 \mathrm{~mm}, 3 \mu \mathrm{m})$; (B) SeQuant ZIC-HILIC column $\left(150 \mathrm{~mm} \times 4.6 \mathrm{~mm}, 5 \mu \mathrm{m}, 200^{\circ} \mathrm{A}\right)$; (C) XAmide column $(150 \mathrm{~mm} \times 4.6 \mathrm{~mm}$, $5 \mu \mathrm{m})$; (D) TSKgel Amide-80 column $(150 \mathrm{~mm} \times 4.6 \mathrm{~mm}, 5 \mu \mathrm{m})$; (E) Click XIon column $(150 \mathrm{~mm} \times 4.6 \mathrm{~mm}, 5 \mu \mathrm{m})$. Isocratic elution with acetonitrile/water $(80 / 20$, v/v); flow rate: $1 \mathrm{~mL} / \mathrm{min}$; temperature: $30^{\circ} \mathrm{C}$; UV detection: $203 \mathrm{~nm}$.

Fig. 2. LC-UV (300 nm) chromatograms of Fr. 24 on an XTerra MS C18 column (5 $\mu \mathrm{m}, 150 \mathrm{~mm} \times 2.1 \mathrm{~mm}$, I.D.) under RPLC mode with Method E in Table 1 (A) and a Click-CD column $(5 \mu \mathrm{m}, 150 \mathrm{~mm} \times 4.6 \mathrm{~mm}$, I.D., laboratory-made $)$ under HILIC mode with Method D in Table 1 (B); column temperature: $30{ }^{\circ} \mathrm{C}$. Different sets of peak numbers were marked on the two chromatograms.

Fig. 3. Separations of alkaloids components extracted from a TCM Corydalis yanhusuo Wang on C18HCE column (a and b) and ODS columns for comparison ((c) Zorbax Eclipse $5 \mu \mathrm{m}$ XDB C18; (d) Atlantis $5 \mu \mathrm{m}$ T3 C18; (e) Xbridge $3.5 \mu \mathrm{m} \mathrm{C18}$; (f) XTerra $5 \mu \mathrm{m} \mathrm{C18}$; (g) inspire $5 \mu \mathrm{m} \mathrm{C18}$; (h) spursil EP $5 \mu \mathrm{m} \mathrm{C18}$; (i) TSKgel 3 $\mu$ m ODS-100V; (j) self-made $5 \mu \mathrm{m} \mathrm{C18/C1)}$. Conditions: mobile phase (A) $0.1 \%$ formic acid water, (B) acetonitrile; gradient for C18HCE: 0-30 min, 0\% $\rightarrow 30 \% \mathrm{~B}$ and gradient for commercial columns: $0-30 \mathrm{~min}, 5 \% \rightarrow 35 \% \mathrm{~B} ; 30-40 \mathrm{~min}, 35 \% \rightarrow 60 \% \mathrm{~B}$; injection volume: (a, c-i) $50 \mu \mathrm{L}$ and (b) $100 \mu \mathrm{L}$; flow rate: $1.0 \mathrm{~mL} / \mathrm{min}$; UV detection: $254 \mathrm{~nm}$.

Fig. 4. Chromatograms of Fr.7 on (A) homemade polar-copolymerized C18 (C18HC) column $(150 \mathrm{~mm} \times 4.6 \mathrm{~mm})$ and commercial columns ((B) Atlantis $5 \mu \mathrm{m}$ T3 C18; (C) TSK gel $3 \mu \mathrm{m}$ ODS-100V C18; (D) Spursil EP $5 \mu \mathrm{m}$ C18; (E) XBridge $3.5 \mu \mathrm{m}$ C18; (F) Zorbax Eclipse $5 \mu \mathrm{m}$ XDB C18; (G) Inspire $5 \mu \mathrm{m}$ C18). 


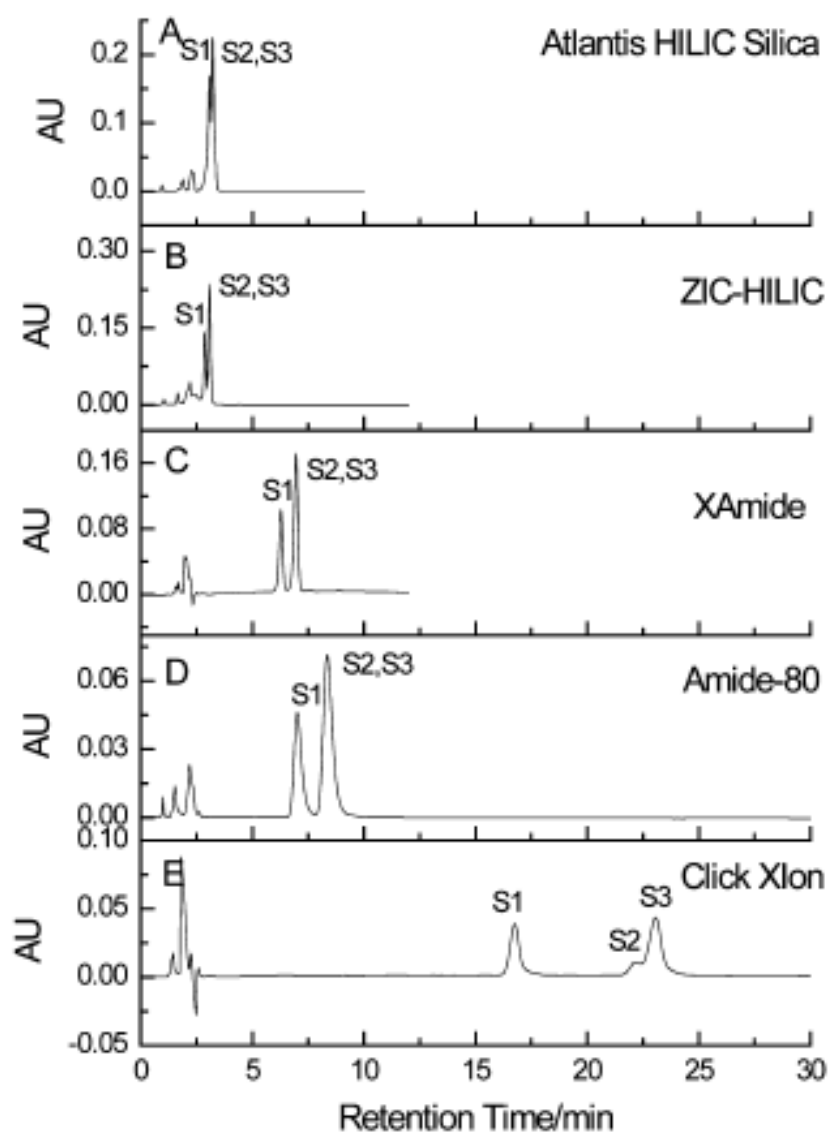

Fig. 1 


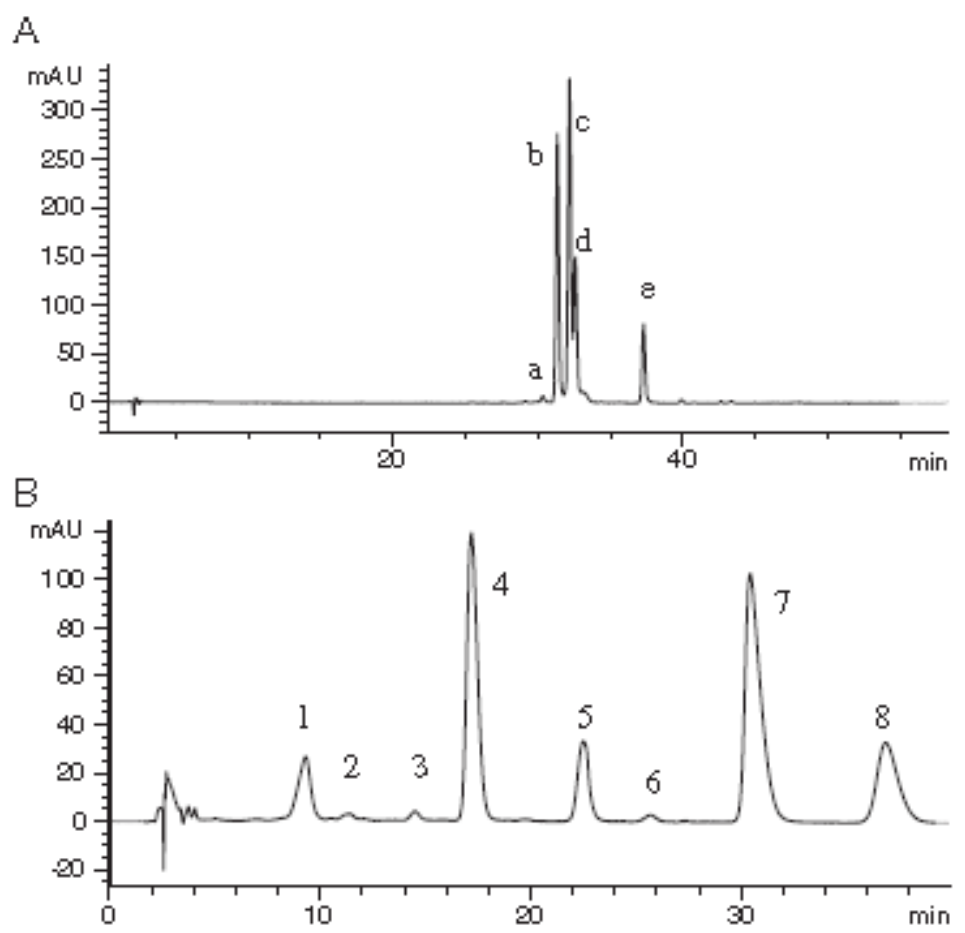

Fig. 2 


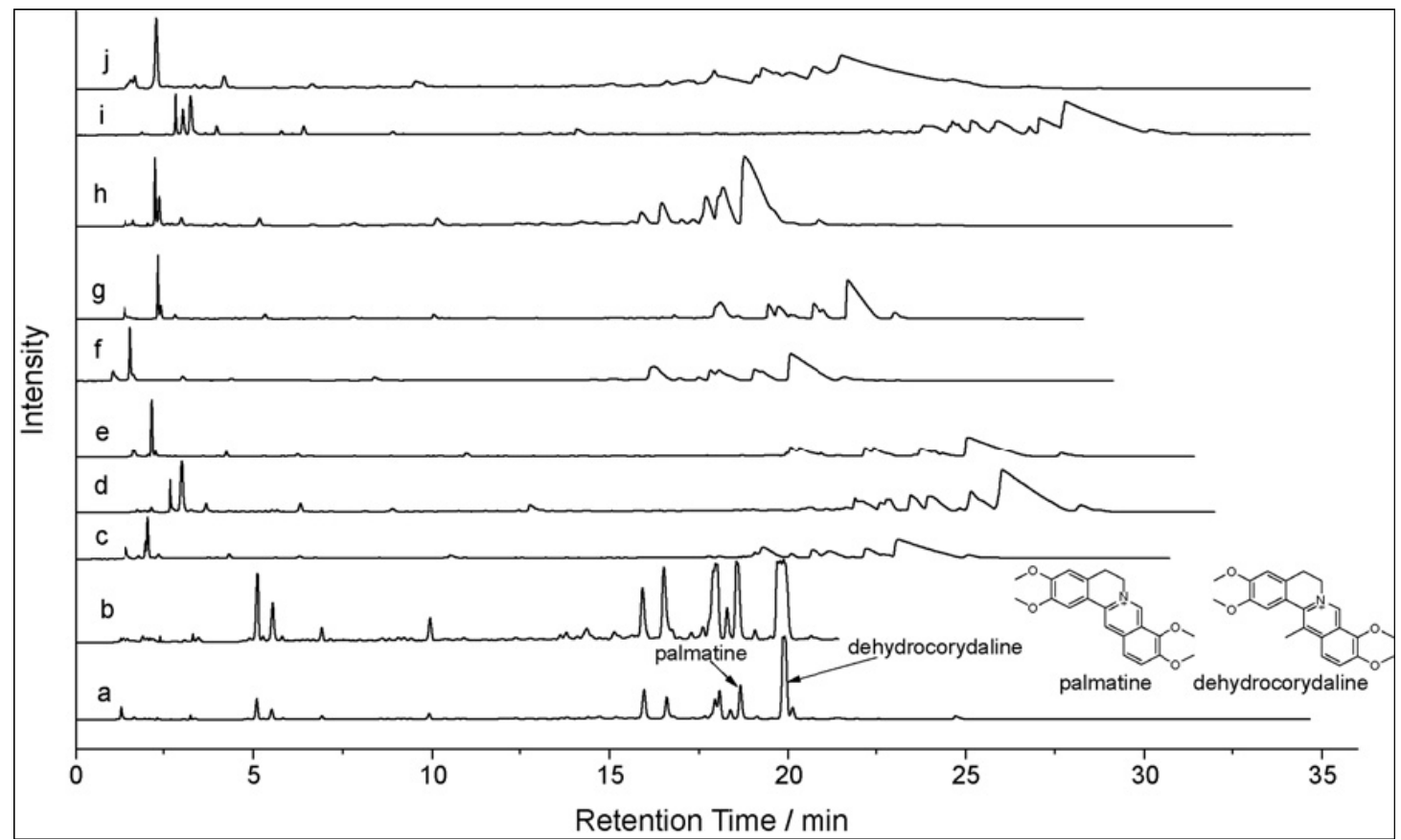

Fig. 3 

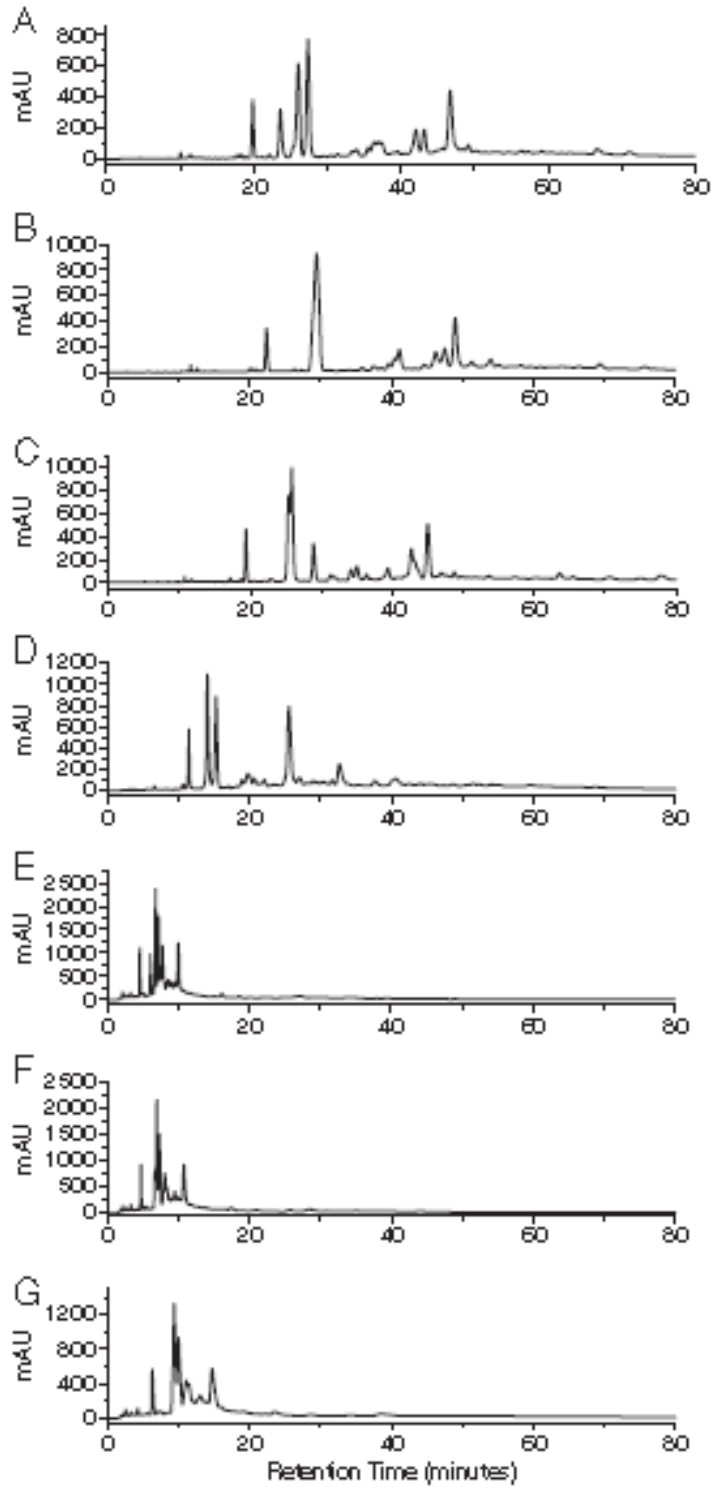

Fig. 4 
Table 1. The application of UHPLC systems in the analysis of TCMs

\begin{tabular}{|c|c|c|c|c|}
\hline Source & Compound & Column & Stationary phase & Ref. \\
\hline Uncaria rhynchophylla & Indole alkaloids & $\begin{array}{l}100 \mathrm{~mm} \times \\
2.1 \mathrm{~mm} \text { i.d. }\end{array}$ & $\begin{array}{l}1.7 \mu \mathrm{m} \text { Acquity } \\
\text { BEH C18 }\end{array}$ & [94] \\
\hline Murraya exotica & Coumarins & $\begin{array}{l}100 \mathrm{~mm} \times \\
2.1 \mathrm{~mm} \text { i.d. }\end{array}$ & $\begin{array}{l}1.7 \mu \mathrm{m} \text { Acquity } \\
\text { BEH C18 }\end{array}$ & [95] \\
\hline SiWu Decoction * & - & $\begin{array}{l}100 \mathrm{~mm} \times \\
2.1 \mathrm{~mm} \text { i.d. }\end{array}$ & $\begin{array}{l}1.7 \mu \mathrm{m} \text { Acquity } \\
\text { BEH C18 }\end{array}$ & [96] \\
\hline Chuanxiong Rhizoma & $\begin{array}{l}\text { Ferulic acid, senkyunolide } \\
\text { I and senkyunolide } \mathrm{H}\end{array}$ & $\begin{array}{l}50 \mathrm{~mm} \times \\
2.1 \mathrm{~mm} \text { i.d. }\end{array}$ & $\begin{array}{l}1.7 \mu \mathrm{m} \text { Acquity } \\
\text { BEH C18 }\end{array}$ & [23] \\
\hline $\begin{array}{l}\text { Coptis chinensis } \\
\text { Franch. (Huanglian) }\end{array}$ & - & $\begin{array}{l}50 \mathrm{~mm} \times \\
2.1 \mathrm{~mm} \text { i.d. }\end{array}$ & $\begin{array}{l}1.7 \mu \mathrm{m} \text { Acquity } \\
\text { BEH C18 }\end{array}$ & [97] \\
\hline $\begin{array}{l}\text { Astragalus } \\
\text { membranaceus } \text { Fisch }\end{array}$ & - & $\begin{array}{l}100 \mathrm{~mm} \times \\
2.1 \mathrm{~mm} \text { i.d. }\end{array}$ & $\begin{array}{l}1.7 \mu \mathrm{m} \text { Acquity } \\
\text { BEH C18 }\end{array}$ & [98] \\
\hline $\begin{array}{l}\text { Plantaginis Herba and } \\
\text { Plantaginis Semen }\end{array}$ & Phenylethanoid glycosides & $\begin{array}{l}50 \mathrm{~mm} \times \\
2.1 \mathrm{~mm} \text { i.d. }\end{array}$ & $\begin{array}{l}1.7 \mu \mathrm{m} \text { Acquity } \\
\text { BEH C18 }\end{array}$ & [99] \\
\hline $\begin{array}{l}\text { Dioscorea zingiberensis } \\
\text { C. H. Wright }\end{array}$ & Saponins & $\begin{array}{l}100 \mathrm{~mm} \times \\
2.1 \mathrm{~mm} \text { i.d. }\end{array}$ & $\begin{array}{l}1.7 \mu \mathrm{m} \text { Acquity } \\
\text { BEH C18 }\end{array}$ & [89] \\
\hline $\begin{array}{l}\text { Bufo bufo gargarizans } \\
\text { Cantor }\end{array}$ & Bufadienolides & $\begin{array}{l}100 \mathrm{~mm} \times \\
2.1 \mathrm{~mm} \text { i.d. }\end{array}$ & $\begin{array}{l}1.7 \mu \mathrm{m} \text { Acquity } \\
\text { BEH C18 }\end{array}$ & [100] \\
\hline Yin Chen Si Ni Tang * & Aconitum alkaloids & $\begin{array}{l}100 \mathrm{~mm} \times \\
2.1 \mathrm{~mm} \text { i.d. }\end{array}$ & $\begin{array}{l}1.7 \mu \mathrm{m} \text { Acquity } \\
\text { BEH C18 }\end{array}$ & [101] \\
\hline Wu-tou decoction $*$ & $\begin{array}{l}\text { Alkaloids, monoterpene } \\
\text { glycosides, } \\
\text { saponins, flavones and } \\
\text { flavone glycosides were } \\
\text { identified }\end{array}$ & $\begin{array}{l}50 \mathrm{~mm} \times \\
2.1 \mathrm{~mm} \text { i.d. }\end{array}$ & $\begin{array}{l}1.7 \mu \mathrm{m} \text { Acquity } \\
\text { BEH C18 }\end{array}$ & [102] \\
\hline $\begin{array}{l}\text { Shuang-Huang-Lian } \\
\text { oral liquid * }\end{array}$ & $\begin{array}{l}\text { Flavonoids, quinic acid } \\
\text { derivatives, saponins and } \\
\text { phenylethanoid glycosides }\end{array}$ & $\begin{array}{l}100 \mathrm{~mm} \times \\
2.1 \mathrm{~mm} \text { i.d. }\end{array}$ & $\begin{array}{l}1.7 \mu \mathrm{m} \text { Acquity } \\
\text { BEH C18 }\end{array}$ & [103] \\
\hline Asari Radix et Rhizoma & Dodecatetraenamides A, B & $\begin{array}{l}100 \mathrm{~mm} \times \\
2.1 \mathrm{~mm} \text { i.d. }\end{array}$ & $\begin{array}{l}1.7 \mu \mathrm{m} \text { Acquity } \\
\text { BEH C18 }\end{array}$ & [104] \\
\hline
\end{tabular}


Table 1. Continued

\begin{tabular}{|c|c|c|c|c|}
\hline Source & Compound & Column & $\begin{array}{l}\text { Stationary } \\
\text { phase }\end{array}$ & Ref. \\
\hline Sparganii Rhizoma & Phenolic compounds & $\begin{array}{l}100 \mathrm{~mm} \\
\times \quad 2.1 \\
\text { mm i.d. }\end{array}$ & $\begin{array}{l}1.7 \mu \mathrm{m} \text { Acquity } \\
\text { BEH C } 18\end{array}$ & [22] \\
\hline Chinese eaglewood & $\begin{array}{l}\text { 5,6,7,8-tetrahydro-2-(2-phenylethyl) } \\
\text { chromones (THPECs) }\end{array}$ & $\begin{array}{l}100 \mathrm{~mm} \\
\times \quad 2.1 \\
\text { mm i.d. }\end{array}$ & $\begin{array}{l}1.7 \mu \mathrm{m} \text { Acquity } \\
\text { BEH C } 18\end{array}$ & {$[105]$} \\
\hline $\begin{array}{l}\text { Shenqi Yiqi Guben } \\
\text { Tablet* }\end{array}$ & $\begin{array}{l}\text { Paeoniflorin, ginsenoside } \mathrm{Re} \text {, } \\
\text { ginsenoside } \mathrm{Rg} 1, \quad \text { forsythin, } \\
\text { ginsenosides } \mathrm{Rb} 1 \text {, and astragaloside }\end{array}$ & $\begin{array}{l}50 \mathrm{~mm} \times \\
2.1 \mathrm{~mm} \\
\text { i.d. }\end{array}$ & $\begin{array}{l}1.7 \mu \mathrm{m} \text { Acquity } \\
\text { BEH C } 18\end{array}$ & {$[106]$} \\
\hline $\begin{array}{l}\text { Guge Fengtong } \\
\text { preparation * }\end{array}$ & - & $\begin{array}{l}50 \mathrm{~mm} \times \\
2.1 \mathrm{~mm} \\
\text { i.d. }\end{array}$ & $\begin{array}{l}1.7 \mu \mathrm{m} \text { Acquity } \\
\text { BEH C18 }\end{array}$ & {$[107]$} \\
\hline $\begin{array}{l}\text { Parasenecio species } \\
\text { and Senecio species }\end{array}$ & Pyrrolizidine alkaloids & $\begin{array}{l}100 \mathrm{~mm} \\
\times \quad 2.1 \\
\text { mm i.d. }\end{array}$ & $\begin{array}{l}1.7 \mu \mathrm{m} \text { Acquity } \\
\text { BEH C18 }\end{array}$ & {$[108]$} \\
\hline $\begin{array}{l}\text { Sanhuang Xiexin } \\
\text { Tang * and Fuzi } \\
\text { Xiexin Tang * }\end{array}$ & - & $\begin{array}{l}50 \mathrm{~mm} \times \\
2.1 \mathrm{~mm} \\
\text { i.d. }\end{array}$ & $\begin{array}{l}1.7 \mu \mathrm{m} \text { Acquity } \\
\text { BEH C18 }\end{array}$ & [24] \\
\hline Piper longum L. & $\begin{array}{l}\text { Piperine, pipernonatine, } \\
\text { guineensine and N-isobutyl-2E, } \\
\text { 4E-octadecadienamide }\end{array}$ & $\begin{array}{l}100 \mathrm{~mm} \\
\times \quad 2.1 \\
\text { mm i.d. }\end{array}$ & $\begin{array}{l}1.8 \mu \mathrm{m} \text { Acquity } \\
\text { HSS T3 }\end{array}$ & {$[109]$} \\
\hline Penthorum chinense & - & $\begin{array}{l}150 \mathrm{~mm} \\
\times \quad 2.1 \\
\text { mm i.d. }\end{array}$ & $\begin{array}{l}1.7 \mu \mathrm{m} \text { Acquity } \\
\text { HSS T3 }\end{array}$ & {$[110]$} \\
\hline Radix Glycyrrhizae & $\begin{array}{l}\text { Liquiritin, apioside, liquiritin, } \\
\text { liquiritigenin, glycyrrhizic acid and } \\
\text { glycyrrhetinic acid }\end{array}$ & $\begin{array}{l}50 \mathrm{~mm} \times \\
2.1 \mathrm{~mm} \\
\text { i.d. }\end{array}$ & $\begin{array}{l}1.8 \mu \mathrm{m} \text { Acquity } \\
\text { HSS T3 }\end{array}$ & [111] \\
\hline Fructus corni & - & $\begin{array}{l}100 \mathrm{~mm} \\
\times \quad 2.1 \\
\text { mm i.d. }\end{array}$ & $\begin{array}{l}1.8 \mu \mathrm{m} \text { Acquity } \\
\mathrm{HSS} \text { T3 }\end{array}$ & {$[112]$} \\
\hline Astragalus & - & $\begin{array}{l}50 \mathrm{~mm} \times \\
2.1 \mathrm{~mm} \\
\text { i.d. }\end{array}$ & $\begin{array}{l}1.8 \mu \mathrm{m} \text { Acquity } \\
\text { HSS T3 }\end{array}$ & {$[113]$} \\
\hline $\begin{array}{l}\text { Ganoderma lucidum } \\
\text { in rat }\end{array}$ & - & $\begin{array}{l}100 \mathrm{~mm} \\
\times \quad 2.1 \\
\text { mm i.d. }\end{array}$ & $\begin{array}{l}1.8 \mu \mathrm{m} \text { Acquity } \\
\text { HSS T3 }\end{array}$ & [93] \\
\hline $\begin{array}{l}\text { White and red } \\
\text { ginseng }\end{array}$ & Ginsenoside & $\begin{array}{l}100 \mathrm{~mm} \\
\times \quad 2.1 \\
\text { mm i.d. }\end{array}$ & $\begin{array}{l}1.8 \mu \mathrm{m} \text { Acquity } \\
\text { HSS T3 }\end{array}$ & [21] \\
\hline
\end{tabular}


Table 1. Continued

\begin{tabular}{|c|c|c|c|c|}
\hline Source & Compound & Column & Stationary phase & Ref. \\
\hline $\begin{array}{l}\text { Shaoyao-Gancao } \\
\text { decoction * }\end{array}$ & - & $\begin{array}{l}100 \mathrm{~mm} \times \\
2.1 \mathrm{~mm} \text { i.d. }\end{array}$ & $\begin{array}{l}1.8 \mu \mathrm{m} \quad \text { Acquity } \\
\text { HSS T3 }\end{array}$ & [114] \\
\hline SiJunZiTang * & $\begin{array}{l}\text { Ginsenosides, flavonoids, } \\
\text { triterpenoid }\end{array}$ & $\begin{array}{l}100 \mathrm{~mm} \times \\
2.1 \mathrm{~mm} \text { i.d. }\end{array}$ & $\begin{array}{l}1.8 \mu \mathrm{m} \text { Acquity } \\
\text { HSS T3 }\end{array}$ & [91] \\
\hline Carthamus tinctorius L. & $\begin{array}{l}\text { Quinochalcone } \\
\text { C-glycosides }\end{array}$ & $\begin{array}{l}100 \mathrm{~mm} \times \\
2.1 \mathrm{~mm} \text { i.d. }\end{array}$ & $\begin{array}{l}1.7 \mu \mathrm{m} \quad \text { Acquity } \\
\text { BEH Shield RP18 }\end{array}$ & [115] \\
\hline $\begin{array}{l}\text { LiuweiDihuang } \\
\text { preparations * }\end{array}$ & - & $\begin{array}{l}100 \mathrm{~mm} \times \\
2.1 \mathrm{~mm} \text { i.d. }\end{array}$ & $\begin{array}{l}1.8 \mu \mathrm{m} \quad \text { Agilent } \\
\text { Zorbax SB-C18 }\end{array}$ & [92] \\
\hline $\begin{array}{l}\text { Songling Xuemaikang } \\
\text { capsules * }\end{array}$ & - & $\begin{array}{l}150 \mathrm{~mm} \times \\
2.1 \mathrm{~mm} \text { i.d. }\end{array}$ & $\begin{array}{l}1.8 \mu \mathrm{m} \text { Agilent } \\
\text { Eclipse Pluse } \mathrm{C} 18\end{array}$ & [116] \\
\hline $\begin{array}{l}\text { Shenqi } \quad \text { Fuzheng } \\
\text { Injection } *\end{array}$ & $\begin{array}{l}\text { Organic acids, amino } \\
\text { acids, oligosaccharides, } \\
\text { alkaloids, nucleosides, } \\
\text { phenylpropanoids, } \\
\text { polyacetylenes, flavonoids, } \\
\text { isoflavonoids and saponins }\end{array}$ & $\begin{array}{l}100 \mathrm{~mm} \times \\
2.1 \mathrm{~mm} \text { i.d. }\end{array}$ & $\begin{array}{l}1.8 \mu \mathrm{m} \text { Agilent } \\
\text { Eclipse Pluse } \mathrm{C} 18\end{array}$ & [117] \\
\hline Wenxin granules * & $\begin{array}{ll}\text { Notoginsenoside } & \text { R1, } \\
\text { ginsenoside Rg1 and } \\
\text { ginsenoside Rb1 }\end{array}$ & $\begin{array}{l}50 \mathrm{~mm} \times \\
2.1 \mathrm{~mm} \text { i.d. }\end{array}$ & $\begin{array}{l}1.8 \mu \mathrm{m} \quad \text { Agilent } \\
\text { Eclipse Pluse } \mathrm{C} 18\end{array}$ & [118] \\
\hline $\begin{array}{l}\text { Huo Luo Xiao Ling } \\
\text { Dan* }\end{array}$ & $\begin{array}{l}\text { Alkaloids, monoterpene } \\
\text { glycosides, iridoids, } \\
\text { phenolic acids, and } \\
\text { tanshinones, coumarins, } \\
\text { lactones, flavones, and } \\
\text { their glycosides, } \\
\text { triterpenes, and triterpene } \\
\text { saponins }\end{array}$ & $\begin{array}{l}75 \mathrm{~mm} \times \\
3.0 \mathrm{~mm} \text { i.d. }\end{array}$ & $\begin{array}{l}2.2 \mu \mathrm{m} \text { Shim-pack } \\
\text { XRODS II C18 }\end{array}$ & [119] \\
\hline $\begin{array}{l}\text { Metabolites } \\
\text { morroniside }\end{array}$ & - & $\begin{array}{l}100 \mathrm{~mm} \times \\
2.1 \mathrm{~mm} \text { i.d. }\end{array}$ & $\begin{array}{l}1.7 \mu \mathrm{m} \text { Syncronis } \\
\mathrm{C} 18\end{array}$ & [120] \\
\hline $\begin{array}{l}\text { Euphorbiae pekinensis } \\
\text { Radix }\end{array}$ & & $\begin{array}{l}100 \mathrm{~mm} \times \\
2.0 \mathrm{~mm} \text { i.d. }\end{array}$ & $\begin{array}{l}2.0 \mu \mathrm{m} \text { CAPCELL } \\
\text { PAK C } 18\end{array}$ & [121] \\
\hline
\end{tabular}

